\title{
$\bigcirc$ ator e o espectador - \\ Sobre as diferentes funções da linguagem na apresentação de si mesmo no Brasil e na Alemanha
}

Ulrike Schröder*

\begin{abstract}
The article presents an analysis of different speech styles used by participants of the German speech community in contrast to the Brazilian one, based on examples of interviews made in both cultures. After the illustration of the different language uses, the article's focus will be on the communicative functions the styles in each community. So, we find the phatic, poetic and expressive function more dominant in the Brazilian speech, whereas the use of the referential and the metalinguistic function seem to be more common in the speech of the German respondents. It is therefore possible to establish the dichotomy between the actor and the spectator in a metaphorical sense to summarize these contrasting functions. Finally, the fact in which these results can in part be explicated by their embedding in different cultural and historical backgrounds, emphasizing the Brazilian speech community as a more heterogenous and baroque, compared with the German one which tends to be more homogenous and (self)-observing will be shown.
\end{abstract}

Keywords: Speech Community; Speech style; Communicative Functions.

Ulrike Schröder é Leitora do DAAD e Professora Visitante na Universidade Federal de Minas Gerais (FALE e FAFICH). Trabalha nas áreas das Ciências Sociais Aplicadas e da Lingüística. 
Zusammenfassung: Basierend auf Interviewsausschnitten in beiden Kulturen, werden in dem Artikel unterschiedliche Redestile der deutschen und der brasilianischen Kommunikationsgemeinschaft vorgestellt. Nach einer Illustration des divergierenden Sprachgebrauchs werden die kommunikativen Funktionen fokussiert, die den Sprechweisen in der jeweiligen Gemeinschaft zukommen. In der brasilianischen Rede dominieren die phatische, die poetische und die expressive Funktion, in der deutschen dagegen finden sich häufigere Verwendungen der referentiellen und metalinguistischen Funktion. Zusammenfassen lassen sich diese gegensätzlichen Tendenzen am besten mit der metaphorischen Dichotomisierung von Akteur und Betrachter. Außerdem wird gezeigt, wie diese Resultate teilweise dadurch erklärt werden können, daß man sie in einen kulturgeschichtlichen Hintergrund einbettet, wobei die Charakterisierung der brasilianischen Kultur als im Vergleich zur deutschen eher heterogen und barock im Vordergrund steht; die deutsche Kultur hingegen erscheint im Vergleich zur brasilianischen als tendenziell homogener und (selbst)beobachtender.

Stichwörter: Kommunikationsgemeinschaft; Redestil; kommunikative Funktionen.

Palavras-chave: Comunidade de fala; estilo de fala; funções comunicativas.

\section{Introdução}

O ponto de partida do estudo de campo apresentado neste artigo forma a suposição de que todos os universos de sentido nos quais os participantes em uma cultura específica se movem todos os dias podem ser reduzidos a um contexto específico de ações comunicativas. Devido aos pontos de vista diferentes dos quais homens diferentes atuam de modo comunicativo, também surgem construtos de realidade diferentes. Por conseguinte, realidade tem que ser entendida como a respectiva soma específica de sistemas de relevância e de mundos de sentido criados primeiramente a partir da linguagem. Uma vez criados, estes mundos de sentido, por sua vez, estruturam e estampam também os conceitos de vida e as ações cotidianas práticas dos participantes de uma cultura de modo que podemos falar de um processo recíproco: um processo de internalização, externalização e modificação de mundo a partir de processos comunicativos (Berger \& LuCKMANN 1967: 183ss). Dentro deste processo, 
encontra-se a força reflexiva da língua: se a língua de uma comunidade cultural é responsável pela constituição e estruturação de domínios de experiência próprios, as categorias de linguagem, uma vez estabelecidas, servem a uma extensão permanente de quadros cognitivos, assim como à sua transferência para domínios de sentido que ainda precisam ser estruturados. Em conformidade com isso, poderiam ser revelados conceitos de realidade divergentes de duas comunidades culturais através de uma reconstrução de estilos comunicativos dos participantes de uma cultura e dos seus conceitos sobre família, trabalho, amor, passado ou futuro.

O estudo parte dessas condições iniciais ao supor uma conexão entre os respectivos panos de fundo históricos das comunidades de fala brasileira e alemã e os traços típicos dos estilos de fala de seus participantes. Aí, serão ilustrados os divergentes estilos de fala nos cotidianos alemão e brasileiro com base nos extratos das entrevistas da pesquisa Brasilianische und deutsche Wirklichkeiten. Eine vergleichende Fallstudie zu kommunikativ erzengten Sinnwelten, realizada em 2000/2001 (cf. SCHRÖDER 2003).

\section{Método}

Partindo das construções que são responsáveis pela criação da vida cotidiana, o sociólogo Alfred ScHÜTZ (1971) afirma que também as ciências não têm nenhum acesso privilegiado à realidade. Ele fala das construções de segundo grau para realçar que não se trata de declarações que são feitas de um ponto de referência externo, mas, sim, de declarações cujas raízes têm que ser procuradas na vida cotidiana. A pesquisa baseia-se nessa diferenciação que propõe que cada método que deve servir para uma investigação de conceitos significativos de uma cultura ou subcultura, primeiramente, tem que se direcionar à perspectiva do entrevistado. Como ScHütz (1971) formulou claramente, numa superação da perspectiva objetivista, a pergunta central teria que passar da pergunta $O$ que o mundo social significa para o observador? para a pergunta $O$ que o mundo social significa para o ator observado dentro desse mundo, e o que ele mesmo quis dizer com sua atividade nele?

The safeguarding of the subjective point of view is the only but sufficient guarantee that the world of social reality will not be replaced 
by a fictional non-existing world constructed by the scientific observer (SCHÜTZ 1971: 8).

Assim, as perguntas dos questionários desse estudo de campo comparativo, assim como as entrevistas, foram fundados neste procedimento qualitativo: foram elaboradas perguntas abrangantes como, por exemplo, O que significa família para você? para as pessoas darem respostas dissertativas a partir das quais poderia ser feita uma análise dos conceitos, metáforas, estruturas etc. divergentes. Havia quatro grupos: o grupo dos estudantes alemães, o dos estudantes brasileiros, o dos não-estudantes brasileiros e o dos não estudantes alemães. A condição para o grupo dos não-estudantes era que eles não estudassem e nunca tivessem estudado numa universidade. Os entrevistados foram escolhidos segundo o princípio de aleatoriedade mas era necessário obedecer a alguns critérios: todos tinham entre 20 e 30 anos, metade mulheres, metade homens, e foi importante que eles viessem de regiões diversas do respectivo país. No total, foram realizados 800 questionários (200 em cada grupo) e 40 entrevistas (10 em cada grupo). No centro da pesquisa, estabeleceu-se uma comparação entre Alemanha e Brasil, considerando a estruturação simbólica feita desses universos significativos pelos entrevistados.

\section{Estilo de fala e funções comunicativas}

Baseando-se no gênero entrevista que, na verdade, representa uma situação comunicativa artificial, embora mostre cruzamentos com a conversação cotidiana não-pragmática devido às perguntas que serviam como estímulo para falar livremente, a questão de interesse refere-se exclusivamente ao estilo de fala divergente em relação a sua função cultural nas comunidades de fala brasileira e alemã e não a outros aspectos de conteúdo ou aspectos lingüísticos. Refiro-me a estilo de fala e não a estilo comunicativo, para realçar a limitação da presente abordagem a uma análise do comportamento verbalvocal. Ponto de partida para uma análise do estilo de fala remete à classificação das seis funções comunicativas de Dell HyMEs (1961): ${ }^{1}$

Essas funções da língua, primeiramente, são descritas por Roman JAKOBSON (1971) que estende as três funções (referencial, expressiva e apelativa) de Karl 
$>$ Expressive (emotiva)

$>$ Directive (imperativa ou injuntiva)

$>$ Referential (referencial, cognitiva ou denotativa)

$>$ Poetic (poética)

$>$ Phatic (fática)

$>$ Metalinguistic (metalingüística ou autoreferencial)

Esta classificação, sem dúvida, tem que ser entendida de modo idealizado, isto é, na situação concreta fundem-se as funções diversas. Todavia, o ponto decisivo para esta análise é a averiguação de que, nas contribuições brasileiras, obviamente outras funções comunicativas vêm à luz do que naquelas dos alemães. Os exemplos dados apresentam uma escolha de todos os textos e apresentam uma tendência observada em todas as entrevistas.

\section{Análise dos estilos de fala divergentes na apresentação de si mesmo}

\section{1 $\mathrm{O}$ ator}

O fato de no Brasil uma "schleifenlose Realisierung" de comunicação que pretende "optimale Kürze und Effektivität" (SANDIG 1986: 193) não ter a mesma importância do que na Alemanha, já explica o tamanho médio duas vezes maior das entrevistas brasileiras em comparação com as alemãs. No Brasil, o modo de se exprimir reluz devido a um estilo muito mais carregado por elementos dramáticos e poéticos, por jogos de palavra, provérbios e inúmeras variantes estilísticos dos universos de contos de fadas, mitos e sagas. Neste ponto, as funções poética, expressiva e fática da língua alcançam o primeiro plano. Desta forma, muitas declarações das entrevistas são impregnadas por um estilo salientemente enfático, o que dramatiza o dito e

Bühler. Todavia, a classificação de HYMEs corresponde muito mais às necessidades da presente abordagem, porque é definida menos lingüística em um sentido restrito, absorvendo fatores contextuais - o emprego do termo funçöes comunicativas já é testemunha disso. 
serve-se da força persuasiva da língua, sobretudo, ao tentar convencer o outro do dito:

Acho que ser amigo - as pessoas falam que ninguém tem. Eu digo para você que tenho, porque até hoje estive passando dificuldades, coisas ruins. Até hoje, até agora, ainda tô arrumando a minha vida, e tem pessoas que se colocam no meu lado, sabe. Que na hora que eu mais precisei tavam lá comigo, me deu uma força, sabe, me apoiou, me apoiou, sabe, me apoiou. Então, eu tenho pessoas, colegas e amigos. Eu falo para você quem é amigo e quem é colega. Eu tenho isso aí. Eu tenho (SCHRÖDER 2003: 176).

Através da evocação direta ao entrevistador com as expressões "Eu digo para você...", "Eu falo para você..." e das redundâncias, não apenas a força persuasiva do dito é aumentada; por meio de tais elementos estilísticos, além disso, o gênero textual entrevista impessoal conforma-se como uma conversação fictícia, onde a função fática vem à tona. ${ }^{2}$

Meios estilísticos que servem a uma interpretação alegórica ou formulativa do mundo e da realidade, na qual a idéia não é transmitida de modo direto, mas sim, de modo cifrado - por exemplo, através de provérbios ou ditados (exemplo 1) -, têm um efeito transfigurativo. Diferentemente das entrevistas alemãs, figuras retóricas diversas encontram-se em aproximadamente todas as entrevistas brasileiras; nelas observam-se a símile (exemplo 2), gradação com epístrofe (exemplo 3), anáfora (exemplo 4), quiasmo (exemplo 5) e assíndeto com uma dramática em preto-branco (exemplo 6).

Exemplo 1: Tudo mundo tem assim, um jardim do bem e um do mal onde florescem as coisas, né. Vai depender do que você quer cultivar, né (SCHRÖDER 2003: 177).

2 No esquema lingǘstico de JAKOBSON, a função fática apenas deve segurar a continuidade da troca por um feedback interno. Contudo, na perspectiva etnológica já o termo phatic communion associa uma extensão social do termo, no qual todas as formas comunicativas que servem a uma afirmação das ligações sociais são consideradas. Em conformidade com isto, MALINOSWKI (1972: 315) define phatic communion como "type of speech in which ties of union are created by a mere exchange of words". 
Exemplo 2: Boa amizade é uma coisa muito boa porque amizade é como uma flor, precisa de muito trato e muito amor (SCHRÖDER 2003: 178).

Exemplo 3: Onde tô, tô legal. Me sinto bem na casa, no lugar onde eu moro. No estado onde eu moro. No mundo onde eu moro (SCHRÖDER 2003: 179).

Exemplo 4: Eu não faço não, nem assim: de amigo e conhecido. Eu faço assim: de gostar e não gostar. [...] Eu sou muito sensitiva. Eu sou espírita. Eu sou muito sensitiva. Quando eu sinto uma pessoa, eu a chamo, quando não sinto, eu não a chamo (SCHRÖDER 2003: 179).

Exemplo 5: Às vezes, eu faço coisas que eu não sou. E às vezes, eu sou coisas que eu não faço (SCHRÖDER 2003: 179).

Exemplo 6: Porque eu olhava para a minha mãe, falava: -Mas como? Se eu olho para ela, vejo o bem, se olho para ele, vejo o mal (SCHRÖDER 2003: 180).

Embora as perguntas feitas tratem de opiniões e atitudes pessoais quanto a amor, trabalho, família, amizade, passado ou futuro etc., em muitas entrevistas, como também na conversação cotidiana, transparece um estilo de discurso professoral, no qual palavras pertencentes a discursos prontos ocupam o lugar de respostas que chegam diretamente à pergunta:

I: O que significa fažer algo da sua vida para você?

P: Então, eu vejo cada um tem o seu plano de vida. Cada um tem cada um vive de uma forma diferente. Vamos estar de classe média, baixa, alta. Mas, na alta, cada um é diferente do outro. Da baixa, tem um diferente do outro, da média tem um diferente do outro (SCHRÖDER 2003: 185).

Muitas das atitudes apresentadas radicam-se na religião (exemplo 7) ${ }^{3}$, filosofia (exemplo 8$)^{4}$ ou música (exemplo 9) $)^{5}$ e são integradas ao 'discurso' no

Presente em 8 das 20 entrevistas.

Presente em 3 das 20 entrevistas.

Presente em 4 das 20 entrevistas. 
qual a recitação dos mosaicos do respectivo domínio lembra as amostras mnemônicas, típicas de culturas orais. Desta forma, o dito não surge como um produto de pensamentos individuais, mas sim, como uma rapsódia de fragmentos textuais colecionados.

Exemplo 7: Se Deus preparar, se Deus quiser, eu vou fazer. Se ele me dar força, eu vou fazer (SCHRÖDER 2003: 186).

Exemplo 8: E Nietzsche porque - eu acho que jamais houve um cara que chegasse tão perto do absurdo do humano quanto Nietzsche. Ele virou as coisas de cabeça para baixo (SCHRÖDER 2003: 186).

Exemplo 9: Mas o que é legal para mim, é fazer o povo abrir o olho e saber que eles são a maioria. É a mensagem que eu deixo. A realidade do mundo sempre foi e sempre vai ser a nossa periferia. Se a periferia não abre o olho, o mundo vai ter a tendência de cair. [...] A gente não é boneca, a gente não é marionete, entendeu. A gente é livre, fazendo o que a gente quer (SCHRÖDER 2003: 186).

Um instrumento estilístico que se refere exclusivamente à função fática é o jogo de pergunta-(auto-)resposta, também presente em todo o cotidiano, que serve a uma asseguração ritualística de tensão na encenação de si mesmo e que falta na Alemanha: ${ }^{6}$

Bom. Tem um detalhe que marca a minha vida. Por quê? Porque me influenciou bastante... (SCHRÖDER 2003: 187).

Estreitamente entrelaçada com este estilo de fala, é a compreensão do sujeito, cristalizado nas apresentações de si mesmo e correspondente ao papel do heróico. Como peça encenada, o 'verdadeiro' Eu continua às escondidas ou fragmentário, ao passo que o Eu apresentado cresce de modo cênico em temas como orgulho familiar e código de honra (exemplo 10) ${ }^{7}$ ou como o grande lutador (exemplo 11)

Presente em quase todas as entrevistas.

Esse tema aparece em 7 das 20 entrevistas.

8 Esse tema aparece em 5 das 20 entrevistas. 
Exemplo 10: A minha família é uma família de caráter. A minha mãe, o meu pai, a minha avó, os tios, são pessoas honestas assim. Não há um exemplo de desonestidade na minha família. Eles me deram muita segurança para poder, querer ser honesto (SCHRÖDER 2003: 182).

Exemplo 11: Eu participei na seleção do SENAC. O SENAC é uma das empresas mais bem conceituadas nesse país. E eu consegui sozinha. Eu participei em todas as entrevistas. Eu passei em todas as etapas e eu fui aprovada. Então, para mim - é sempre um desafio. Eu adoro desafios. Eu adoro (SCHRÖDER 2003: 182).

\section{$3.2 \bigcirc$ espectador}

Nas respostas alemãs, mostra-se uma transposição do ator ao espectador. Os comentários não são feitos do palco, mas sim, da sala de espetáculo, ou seja, do ponto de vista do (auto-) observador. Ao contrário dos entrevistados brasileiros, a demarcação executa-se mais indiretamente, através do uso bem codificado de expressões de segunda ordem. Aí, especialmente as palavras compostas ad hoc marcam uma característica estilística. Pois elas têm a força de designar cada fato ainda não denominado, no qual se encontra o desejo de uma reflexão e explicação tão detalhadas como possível da experiência do mundo. De acordo com isto, a apresentação de si mesmo efetua-se a partir de uma articulação de originalidade mental por meio das palavras compostas, utilizadas metaforicamente ou valorizando: um entrevistador, por exemplo, distancia-se de "Klischee-Informatikern", que querem "dicke Knete machen" ou "Prestigepositionen bekleiden"; outros de estudantes, que cultivam "Pseudointellektualismus", ou que são "Stubenhocker" ou "Mamasöhnchen"; outros de colegas de trabalho, que adoram "gutbürgerlichen Urlaub" e não fazem nada além de passar o ano inteiro poupando dinheiro „um in den Spießerurlaub zu fahren”, o que parece ser "völliger Schwachsinn" (SCHRÖDER 2003: 189).9

Partindo da função referencial, a linguagem serve à diferenciação, abstração e (auto-) reflexão. Nesta variante, a entrevista parece menos como

9 Essa tendência pode ser observada em todas as entrevistas. 
uma conversação, mas sim, mais como um monólogo introspectivo, no qual também comentários auto-críticos e auto-irônicos ocorrem, apontando que os entrevistados se examinam de um nível de observador do segundo grau: um entrevistado considera-se "spießig" demais para ter um trabalho sem estabilidade; uma outra entrevistada não se considera bastante "straight" para cumprir as exigências do curso de jornalismo; uma outra faz piadas sobre as próprias "Selbstmitleidsphasen" e titula-se como "Dickkopf". Muitos relativizam suas declarações através de comentários como "hört sich vielleicht'n bisschen arrogant jetzt an", “nein, Quatsch”, “das hört sich jetzt blöd an" oder "das hört sich jetzt'n bisschen doof an" (SCHRÖDER 2003: 189). ${ }^{10}$ Tais declarações representam uma relativização antecipada do dito como resposta a uma possível reação apenas imaginada do outro: por um lado, cumprem uma função meta-comunicativa por sua referência às próprias comunicações, e, por outro lado, também podem ser lidas como estratégias de Face-work. ${ }^{11}$ Um estudante diz:

Wann mir was unangenehm ist? [...] Vielleicht, wenn ich'nen neuen Job antrete und die Leute nicht kenne. Aber ich denk mal, das ist ganz normal - dass man vielleicht'n bisschen Angst davor hat, vor neuen Sachen, obwohl, das heißt nicht, dass ich neue Sachen deswegen nicht machen würde (SCHRÖDER 2003: 190).

Sem que alguém tivesse suposto que o entrevistado não seja aberto para coisas novas, ele já apresenta uma defesa feita para uma repreensão tipificada. Então, furtivamente introduz-se o pronome indefinido man, que supõe tacitamente a um grupo inteiro os mesmos padrões de agir e reagir.

Os comentários do metanível podem referir-se a uma classificação das próprias palavras em uma tipificação conhecida. Neste caso, o dito

10 Essa fórmula introdutória ocorre em 10 das 20 entrevistas (e nenhuma vez nas entrevistas brasileiras).

11 O conceito Face-work tem origem na expressão chinesa mianz̧i e refere-se ao prestígio que um falante tenta conseguir em uma situação comunicativa; cf. as estratégias de trabalho de Face em conversações alemãs também a pesquisa de Meireles (2002). 
passa por uma objetivação e é submetida a uma reflexão que também tem a função de preservação da face perante o entrevistador:

I: Möchtest du denn mal mit ihr [seiner Freundin, US] zusammenleben?

P: Also ich mach mir da jetzt keine konkreten Gedanken, - also find ich nicht unattraktiv den Gedanken - ich wüsst jetzt auch nicht, welche Lebensform, also getrennt, zusammen, bla bla [...] (SCHRÖDER 2003: 191).

Neste exemplo, o entrevistado imita a si mesmo preventivamente, através do que se estabelece uma distância diante do dito. Com isto, já pode ser tirada do caminho a suspeita, eventualmente surgida por parte do entrevistador, de que o entrevistado poderia ser um "falador".

O conjunto de mais níveis de reflexão e, juntamente com isso, a autoreferencialidade na qual a função referencial, sob a forma de explicativa, e a função metalingüística ${ }^{12}$ interagem, são mostrados no próximo exemplo, onde uma estudante informa sobre as influências da sua infância da seguinte forma:

Ja, also als Kind hab ich viel gelesen und viel Fernsehen geguckt. Also das waren so zwei Sachen. Und ansonsten viel mit meinen Geschwistern gemacht. Meine Eltern waren nicht ganz so präsent. Die waren beide berufstätig und selbstständig und irgendwie am Arbeiten (SCHRÖDER 2003: 192).

A primeira e a terceira frase representam reflexões do primeiro nível. A segunda frase já é um comentário que sintetiza a primeira, dando-lhe uma forma final fechada e etiquetando-a como resposta à pergunta feita. Ora, a quarta e a quinta frase referem-se à suposição tácita de que, na verdade,

12 Nestes exemplos, a função metalingüística sempre preserva uma ligação forte com a função referencial da língua. O ponto decisivo é, que, nas entrevistas alemãs, o conjunto de ambas funções mostra uma alta autoreferencialidade. Por isso, em comparação com as entrevistas brasileiras, o estilo de fala é menos narrativo e sucessivo, mas sim, mais dedutivo e subordinativo. Os entrevistados referem-se o tempo inteiro a coisas ditas logo antes, definindo-as, classificandoas, concretizando-as, assegurando-as ou esclarecendo algo. 
neste lugar devem ser mencionados os pais, que, no entanto, não tinham relevância. Com isto, ambas as frases representam um nível de reflexão completamente diferente por se referirem apenas a suposições imaginadas do outro.

Além disso, em muitas entrevistas observa-se uma numerosa utilização de atos de fala assertivos como denken / glauben / meinen / schätz̨en / annehmen / vermuten etc., que, através do acréscimo de uma oração principal performativa, alargam a sintaxe e aceleram um distanciamento do dito, promovendo, desta forma, o falar metacomunicativo, menos presente nas entrevistas brasileiras.

\section{Conclusões e encaixamento histórico-cultural dos resultados}

Os resultados mostrados podem ser ligados a diversos fatores de influência, de forma que não é possível dar uma explicação monocausal para as diferenças ilustradas porque sempre se observa um jogo recíproco de elementos variados que são interligados um ao outro. Em seguida, devem ser mencionados alguns desses fatores que podem explicar, em parte, os resultados descritos.

Um índice quanto à pergunta da identidade brasileira que aparece continuamente em estudos de campos diversos é a descrição da sua cultura como uma cultura barroca.

Quando chega no Brasil cerca de cem anos depois da sua florescência na Europa, o barroco entra em cena, inicialmente, vestido como arte erudita. Entretanto, logo a seguir, a tensão alegórica entre a "fuga do mundo" e o "prazer do mundo" absorve mais e mais elementos índio-africanos: é isto que, dentre outros, a arquitetura tropical testemunha com seus ingredientes místicos, sexuais e brincalhões. ${ }^{13}$ Depois da chegada do classicismo nas classes altas, o barroco emigra pouco a pouco até o povo, que enriquece seu folclore com motivos barrocos como, por exemplo, a figura da Virgem Santa:

13 A uma gênese da produção cultural barroca desde a época do colonialismo cf. CÂNDIDO (2000b: 85ss). À tropicalização da arquitetura barroca no Brasil cf. entre outros BASTIDE (1971: 60s). 
No Brasil, sobretudo naqueles séculos, esse estilo equivalia a uma visão - graças à qual foi possível ampliar o domínio do espírito sobre a realidade, atribuindo sentido alegórico à flora, magia à fauna, grandeza sobre-humana aos atos. Poderoso fator ideológico, ele compensa de certo modo a pobreza dos recursos e das realizações; e ao dar transcendência às coisas, fatores e pessoas, transpõe a realidade local à escala do sonho (CÂNDIDo 2000a: 169).

Com o tempo, na sua transculturação, o barroco adentra a vida brasileira por completo; carregado por elementos mágicos, ele torna-se estilo cotidiano que domina muitas conversações habituais até hoje. A força da apresentação, transfiguração e transformação favorece as funções poéticas, fáticas e emotivas que dirigem mais do que na Alemanha os acontecimentos conversacionais no Brasil. A inversão no irreal, fantástico, paradoxo e nãoautêntico, que, justamente, por sua vez, torna a identidade brasileira autêntica, enfrenta a vida como um ato de balança entre diversos papéis e múltiplos universos - neste ponto o malandro, o jeitinho, o jogo de cintura e o cordel de bamba entram em cena - ao passo que, na Alemanha, autenticidade, coerência biográfica e interiorização interagem em um processo recíproco para transferir-se a uma realidade unicamente válida. Essa ambição pré-forma também o universo de linguagem de modo muito mais agudo do que no português do Brasil, que é mais abstrato. Em alemão, quando ao invés de ir a pé / ir de carro / ir de avião / ir de cavalo se fala de gehen / fabren / fliegen / reiten, quando são gerados substantivos compostos - Schlafzimmer, Hörsaal, Schlacbthaus, Schwimmbad, Brutkasten e Waschkë̈che - para definir mais concretamente a característica de um local, quando palavras compostas metafóricas e valorizadoras são criadas para se delimitar dos outros, finalmente, neste ponto articula-se o desejo de ontologizar por meio da língua (cf. WEISGERBER 1950: 198ss).

Há outros índices lingüísticos que correspondem à tendência descrita: é possível observar um crescimento expressivo de palavras compostas dentro da língua alemã no contexto da literalização. A porcentagem média de substantivos compostos dentro de um texto aumenta de $6,8 \%$ na segunda parte do século doze para 18,4\% na segunda metade do século dezessete. Isto acontece porque as palavras compostas tendem a descontextualizar e objetivar os significados das palavras pelo fato de que o conceito relaciona- 
do à palavra não continua dependente da situação, mas sim, é prescrito junto com o composto (cf. Solms 1999: 241). Concomitantemente, o emprego dos Funktionsverbgefüge como in Bewegung setzen, in Betracht ziehen etc., que descrevem um processo mais exatamente, aumenta assim como também a divulgação dos atos de fala assertivos (cf. WOLFF 1994: 147). ÀGEL (1999: 215) vê nessas tendências um despertar da exigência racionalista de uma relação contínua de correspondência entre coisas/fatos, idéias e signos lingüísticos que se consolida quando o ideal de agudeza, de clareza e de decomposição surge em virtude do iluminismo e da literalização da língua. Em contrapartida, sinonímia e polissemia, símbolos do barroco, são desvalorizadas pelos iluministas.

Exatamente nesse ponto, as funções das línguas alemã e brasileira separam-se. Em vista de uma pluralidade de possíveis realidades que resultam de uma cultura heterogênea, não parece adequado aproveitar a língua como instrumento para copiar uma única realidade; as funções poética e fática substituem a descritiva e explicativa. ${ }^{14}$ Segundo o escritor cubano José Lezama Lima (1993: 47), o barroco está presente em toda a cultura americana e apresenta "un arte de la contraconquista" que se abate no repertório de comportamento dos participantes dessas culturas:

O barroco, ou o dionisíaco, ele é vergônico, cheio das peças e permite o exagero, a deformação, a cor. Não é aquela coisa nítida, nua, curtida. São jogos, né. Eu acho que quem mostrou isso foi Glauber Rocha. E também os próprios políticos. A confusão que eles criam. As voltas que eles dão. $\mathrm{O}$ barroco pertence a nós. $\mathrm{E}$ a alma do barroco é o exuberante, contra a regra. Bom. E dentro da fala, também é uma coisa que vem da oralidade. $\mathrm{O}$ barroco, ele fala demais, ele exa-

14 Por isso, quanto aos mundos culturais e mentais na América Latina, o sociólogo Octavio IANNI fala de um labirinto. Eles não seriam simplesmente um reflexo ou uma cópia das modas européias, mas sim, muitas vezes, uma transformação ambígua. O que acontece seria um carnavalização das idéias cartesianas, positivistas, pragmáticas e utilitaristas no terreno brasileiro, onde os imperativos metódicos se desfazem e o chegado se abre para elementos ambíguos. Segundo IANNI (1993: 122ss), disso também resultam o ecletismo e o exotismo da produção científica e literária. 
gera, ele tece, ele exagera as coisas sem necessidade (Melo SiLva 2001). ${ }^{15}$

Como é impossível declarar algo sobre o valor da "verdade" ao se assistir a uma peça barroca no cotidiano brasileiro, também a cansativa procura alemã por coerência e autenticidade perde seu peso. Isto abre espaço para uma certa arbitrariedade quanto à apresentação de si mesmo que agora depende exclusivamente da habilidade artística do ator.

Os sujeitos opostos do ator e do (auto-)espectador também são foco do sociólogo norte-americano Richard SENNETT (1977) na sua abordagem The Fall of Public Man. Nesta, ele contrasta o retorno ao privado com o jogo de papéis no público que era onipresente até os séculos dezoito e dezenove, quando a interação social ainda era realizada inteiramente no palco. Junto com a inovação da individualidade e o avanço da personalidade, a identidade do homem público divide-se em duas partes: no ator e no espectador. $\mathrm{O}$ último aparece como um indivíduo isolado, sem papéis, aspirando a autenticidade:

By contrast, under a system of expression as the presentation of emotion, the man in public has an identity as an actor - an enactor, if you like - and this identity involves him and others in a social bond. Expressions as a presentation of emotion is the actor's job - if for the moment we take that word in a very broad sense; his identity is based on making expression as presentation work. When a culture shifts from believing in presentation of emotion to representation of it, so that individual experiences reported accurately come to seem expressive, then the public man loses a function, and so an identity. As he loses a meaningful identity, expression itself becomes less and less social (SENNETT 1977: 108).

Ora, este lado social da expressão é muito mais presente no Brasil do que na Alemanha. Dramaturgia, exageros, citar provérbios e palestrar sobre a

15 Recorte duma entrevista com a Profa. Dra. Dilma de Melo SILVA da Escola de Comunicações e Artes da USP (Universidade de São Paulo), realizada em 18 de junho de 2001. 
vida são todos meios estilísticos que obedecem a regras públicas e que são ritualizados em alto grau no Brasil. Em contraposição a isto, na Alemanha, por um lado, percebe-se a análise "objetiva" de um ponto de vista observador, por outro lado, a introspecção e a auto-reflexão ocupam o lugar desse estilo brasileiro. Essas tendências alemãs são influenciadas por mais dois fatores histórico-culturais que acompanham a diferenciação funcional da sociedade desde a época do renascimento: a repercussão contínua da escrita à fala e os processos da interiorização que, além da dicotomização descrita da vida privada e pública, também apresentam raízes no protestantismo. Ao invés de um envolvimento em situações naturais, a escrita, como também a auto-observação protestante ${ }^{16}$ sugerem uma diferença entre o pensar e o ser. A consciência e fontes do pensamento inconscientes são ontologizadas e entendidas como espaço estável e mental. Com isto, o homem consegue ocupar-se cada vez mais com si mesmo, como os recortes das entrevistas alemãs citadas ilustram. Deste modo, também SENNETT (1977: 31) descreve o novo mundo da privacidade como um universo tingido psicologicamente, no qual as gratificações do $E u$ aumentam porque as ligações emocionais são desengatadas de outras redes sociais e existem apenas como próprio propósito do individualismo. Teatralidade posiciona-se em uma relação hostil à intimidade, emoções não devem ser mais apenas apresentadas, mas sim, também devem ser sentidas; aí, a expressão pode ser interpretada como signo para o respectivo caráter individual:

Fielding's world, in which masks do not express the nature of the actors, was over; masks were becoming faces (SENNETT 197s: 146).

Lingüisticamente, este retorno à comunidade de fala alemã abate-se no "Weg von der höfisch-repräsentativen zur bürgerlich-individualistischen Literatursprache” (Polenz 1991: 312).

16 Cf. a isso especialmente as abordagens de Max WeBER (1991). 


\section{Referências Bibliográficas}

ÀGEL, Vilmos. "Grammatik und Kulturgeschichte. Die raison graphique am Beispiel der Epistemik.” In: GARDT, Andreas, Ulrike Hass-ZumKEHR u.a. (org.): Sprachgeschichte als Kulturgeschichte, Berlin/New York, Walter de Gruyter 1999, 171-223.

Bastide, Roger. Brasil - Terra de Contrastes. São Paulo, Difusão Européia do Livro 1971.

Berger, Peter L. e Thomas Luckmann. The Social Construction of Reality. A Treatise in the Sociology of Knowledge. London/Allen Lane, The Penguin Press 1967.

Candido, Antonio. A Educação pela Noite \& Outros Ensaios. São Paulo, Editora Ática 2000a.

Candido, Antonio. Literatura e Sociedade. São Paulo, T.A. Queiroz 2000 b.

Hymes, Dell. "Functions of speech: an evolutionary approach.” In: GrubER, Frederick C. (org.): Anthropology and Education, Philadelphia, University of Pennsylvania Press 1961, 55-83.

Ianni, Octavio. O labirinto latino-americano. Petrópolis, RJ, Vozes 1993.

Jakobson, Roman. "Linguistik und Poetik." In: IHWE, Jens (org.): Literaturwissenschaft und Linguistik. Ergebnisse und Perspektiven, Frankfurt am Main, Athenäum 1971, 142-178.

Lima, José Lezama. La expresión americana. México, Fondo de Cultura Económico 1993.

Malinowski, Bronislaw. "The Problem of Meaning in Primitive Language Supplement.” In: Ogden, Charles K. e Ian A. Richards (org.): The Meaning of Meaning. A Study of the Influence of Language upon Thought and of the Science of Symbolism, London, Routledge \& Kegan Paul Ltd. 1972, 296336.

MeIreles, Selma Martins. Dissension and Face-work Strategies in German Dialogues. Tübingen, Max Niemeyer Verlag 2002.

Polenz, Peter von. Deutsche Sprachgeschichte. Vom Spätmittelalter bis zur Gegenwart. Band I. Einführung, Grundbegriffe. Deutsch in der frübbürgerlichen Zeit. Berlin/New York, Walter de Gruyter 1991. 
乞n SANDIG, Barbara. Stilistik der deutschen Sprache. Berlin/New York, de Gruyter 1986.

SCHRÖDER, Ulrike. Brasilianische und deutsche Wirklichkeiten. Eine vergleichende Fallstudie zu kommunikativ erzengten Sinnwelten. Wiesbaden, Deutscher Universitäts-Verlag 2003.

ScHÜTZ, Alfred. Collected Papers II. Studies in Social Theory. The Hague, Martinus Nijhoff 1971.

Sennett, Richard. The Fall of Public Man. New York, Alfred A. Knopf, Inc 1977.

Solms, Hans-Joachim. "Der Gebrauch uneigentlicher Substantivkomposita im Mittel- und Frühneuhochdeutschen als Indikator kultureller Veränderung." In: GARDT, Andreas, Ulrike Hass-ZumKeHr u.a. (org.): Sprachgeschichte als Kulturgeschichte, Berlin/New York, Walter de Gruyter 1999, 225-246.

Weber, Max. Die protestantische Ethik I. Eine Aufsatzsammlung. Gütersloh, Gütersloher Verlagshaus Gerd Mohn 1991.

Weisgerber, Leo. Vom Weltbild der Deutschen Sprache. 1. Halbband: Die inhaltsbezogene Grammatik. Düsseldorf, Pädagogischer Verlag Schwann 1950.

WolfF, Gerhart. Deutsche Sprachgeschichte: ein Studienbuch. Tübingen/Basel, Francke 1994. 